\title{
The Effect of Polymyxin on Plant Roots ${ }^{1}$
}

\author{
A. G. Norman \\ From the Plant Nutrition Project, University of Michigan, Ann Arbor, \\ Michigan
}

Received May 6, 1955

INTRODUCTION

Antibiotics are recognized and selected because of their inhibitory effects on the proliferation or activity of microorganisms. Only relatively recently have their effects on plant growth been studied, mostly in connection with the search for compounds which might be employed to suppress invading plant pathogens (1-5). In such cases the antibiotic should control the pathogen without adversely affecting the host plant. Various antibiotics, however, have been found to be inhibitory or inimical to plant growth $(2,4-10)$.

The experiments reported herein arose from a desire to suppress microbial development on root surfaces in cation-uptake studies. Ordinarily in such work no attempt is made to establish or maintain sterile conditions. Bacterial counts, which will be reported elsewhere, indicated that in young root cultures organisms are present both at large in the medium and on the root surfaces in great numbers. This fact is ordinarily ignored in the reporting or interpretation of uptake studies. Of a number of antibiotics tested to control microbial development in root cultures, none were found to be entirely satisfactory, but several were observed to affect adversely root growth and function at levels which indicated substantial physiological potency. Polymyxin is in this class. Its effect on roots was examined further in the hope that thereby some light might be thrown on its mode of action.

The antibiotic, polymyxin, produced by the organism Bacillus polymyxa, is active in the suppression of gram-negative bacteria $(11,12)$. It is believed to be a basic cyclic polypeptide with mol. wt. about 1200 .

${ }^{1}$ Paper No. 8 from the Plant Nutrition Laboratory, Michigan Memorial Phoenix Project No. 32 of the University of Michigan. 
Several polymyxins have been recognized from different strains of the organism. All contain a $\mathrm{C}_{9}$ saturated fatty acid, believed to be 6-methyloctanoic acid, and either three or four of the following amino acids: $\alpha, \gamma$ diaminobutyric acid, leucine, phenylalanine, threonine, and serine $(13$, 14). The following studies were carried out with polymyxin $B$, which contains the first four amino acids listed. I am indebted to Dr. L. G. Nickell, Chas. Pfizer and Co., Brooklyn, New York, for supplies of this material.

\section{EXPERIMENTAL}

In this paper the growth effects recorded are mostly based on dry matter differences in the roots of young barley seedlings var. Moore or var. Atlas. Lots of 8 g. of seed were soaked for $24 \mathrm{hr}$. in cheesecloth bags just submerged in vigorously aerated water. The seed was then transferred and spread uniformly on 5 -in. circles of polyvinylidene chloride (Saran) screen cloth suspended over cylindrical plastic containers with a volume of $1500 \mathrm{ml}$. in which any nutrients or compounds under test were placed. The culture was aerated gently through a Pyrex fritted gasdispersion tube, and maintuined at $25^{\circ}$ in darkness for 5 days. At this time the roots were cut off immediately below the screen cloth, and dried at $80^{\circ}$ overnight. The experimental system involved only the conversion of reserve material from the endosperm to roots. Reproducible results are readily obtained if the seed batch has high percentage germination and is vigorous and uniform in growth rate.

Moore barley under these conditions has a small absolute requirement for calcium, without which the dry weight of roots at 6 days is significantly lower. This requirement may be met by $1 \times 10^{-4} \mathrm{M} \mathrm{CaSO}_{4}$ or by the addition of an exchangeable calcium source, such as Amberlite IRC-50 (Ca), Amberlite IR-120 (Ca), calcium bentonite, or calcium kaolinite. Though excellent growth was obtained with the clays, it was difficult to remove them entirely from the root surfaces, and for most experimental purposes Amberlite IRC-50 (Ca) was preferred. Two hundred and fifty milligrams of the latter was used in many experiments as the calcium supplement.

At this calcium level, or in the absence of added calcium, root growth of barley seedlings was almost completely inhibited by polymyxin concentrations of 10 p.p.m. or more $\left(10^{-5} M\right.$ approx.), although shoot growth of normal appearance was obtained. The concentration causing $50 \%$ inhibition of roots was somewhat above 5 p.p.m., usually in the neighborhood of 6 p.p.m. Roots in such cultures were less numerous, shorter, and abnormal. The root tip was brownish, and frequently hooked. There seemed to be a tendency to break off about $1 / 4 \mathrm{in}$. back from the tip. Some material sloughed off and became dispersed in the medium. In such cultures the top growth was in no way distinguishable from normal in appearance or height (10-12 cm.). Root growth was clearly far more 


\section{TABLE I}

Effect of Polymyxin on Root Growth of Moore Barley

Root weight in grams, oven-dry, at 6 days from 8 g. air-dry seed

$\begin{array}{ccccc}\begin{array}{c}\text { Polymyxin } \\ \text { p.p.m. }\end{array} & \text { Water } & \mathrm{CaSO}_{4}, 10^{-4} \text { II } & \begin{array}{c}\text { Amberlite IRC-50 } \\ \text { (Ca), 100 mg. }\end{array} & \begin{array}{c}\text { Amberlite IR } \\ \text { (Ca), 250 m }\end{array} \\ 0 & 0.50 & 0.53 & 0.50 & 0.65 \\ 2.5 & 0.36 & 0.42 & 0.43 & 0.48 \\ 5.0 & 0.30 & 0.31 & 0.30 & 0.40 \\ 7.5 & 0.14 & 0.17 & 0.18 & 0.29\end{array}$

sensitive to polymyxin than shoot growth. Typical yields are given in Table I.

The inhibitory effect of 5 p.p.m. polymyxin was found to be repressed if the initial concentration of calcium in the culture was greater than $1 \times 10^{-3} M$, and was almost completely annulled with $1 \times 10^{-2} M$ $\mathrm{CaSO}_{4}$. Root weights at various levels of calcium, with and without polymyxin, are plotted in Fig. 1. Concentrations of $\mathrm{CaSO}_{4}$ in excess of $2.5 \times 10^{-3} M$ caused some growth repression without polymyxin. It is to be noted that in these experiments the solutions were not buffered and the final $\mathrm{pH}$ was below 5.0 in almost all cases.

It was next ascertained that there was a relationship between polymyxin concentration and the calcium reversal of the growth repression

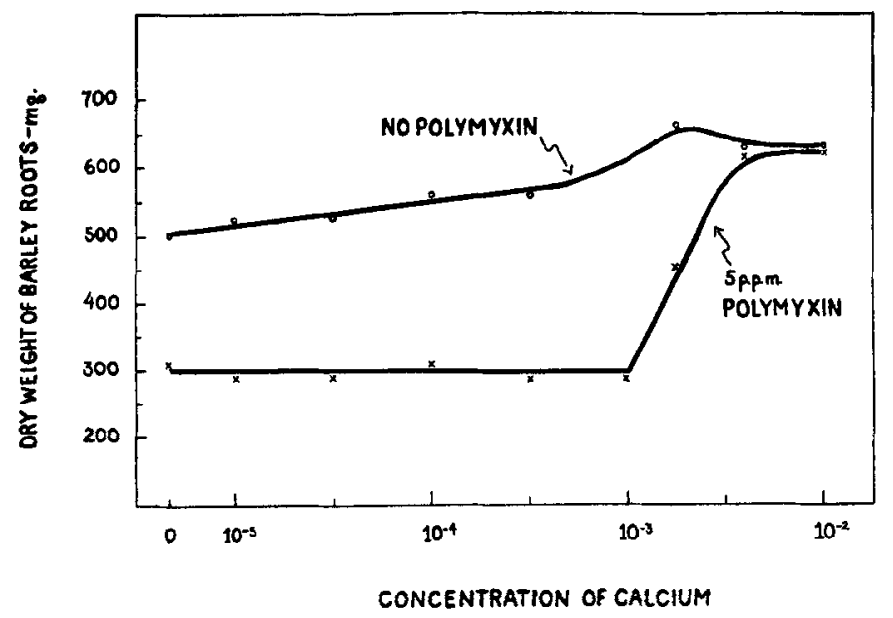

FIg. 1. Repression of polymyxin inhibition of barley root growth by calcium. 
TABLE II

Effect of Polymyxin and Calcium Concentration on Root Growth of Moore Barley Root weight in grams, oven-dry, at 6 days from 8 g. air-dry seed

\begin{tabular}{ccccc} 
Calcium & \multicolumn{4}{c}{ Polymyxin, $p . p . \pi}$. \\
concn. & 0 & 2.5 & 5.0 & 7.5 \\
$1 \times 10^{-4} M$ & & & & \\
$2.5 \times 10^{-3} M$ & 0.53 & 0.42 & 0.31 & 0.17 \\
$1 \times 10^{-2} M$ & 0.66 & 0.53 & 0.45 & 0.35 \\
& 0.63 & 0.64 & 0.63 & 0.64
\end{tabular}

caused by the antibiotic (Table II). This was investigated further at 7.5 p.p.m. polymyxin concentration with a series of levels of calcium (Table III). When plotted, these data indicate a break in the yield curve between 4 and $5 \times 10^{-8} \mathrm{M}$, indicating that some point of equivalence is reached in this region. The break is not sharp enough to establish the "neutralization concentration" unequivocally, but it would appear that the inhibiting effect of $11.25 \mathrm{mg}$. polymyxin was offset in these experiments by approximately $300 \mathrm{mg}$. $\mathrm{Ca}(1 \mathrm{~mole} \mathrm{Ca} / 1.5 \mathrm{~g}$. polymyxin).

No other bivalent cation studied was capable of reversing the inhibitory activity of the polymyxin within those limits of salt concentration that permitted normal root growth (Table IV). Similarly, neither sodium nor potassium in physiologically tolerated concentrations offsets the action of this antibiotic. Simple mixtures of other bivalent cations with calcium yielded inconsistent results, but in general the yields obtained were not much greater than with calcium alone, except when the calcium concentration was already almost high enough to offset the polymyxin inhibition (Table V). The addition of twice the mole concentration of sodium citrate did not depress the calcium reversal of polymyxin inhibi-

TABLE III

Effect of Calcium in Reversal of Barley Root Inhibition by 7.5 p.p.m. Polymyxin

$\begin{array}{ccc}\mathrm{Ca} \text { as } \mathrm{CaSO}_{\text {a per culture }} & \mathrm{Ca} \text { concn. } & \text { Root weight } \\ \text { mg. } & \times 10^{-2} M & \mathrm{~g} . \\ 150 & 2.5 & 0.35 \\ 200 & 3.3 & 0.40 \\ 250 & 4.1 & 0.44 \\ 300 & 5.0 & 0.57 \\ 400 & 6.7 & 0.62 \\ 500 & 8.3 & 0.70\end{array}$

${ }^{a}$ From 8 g. air-dry seed. 
TABLE IV

Effect of Some Bivalent Cations on Barley Root Inhibition by Polymyxin

Root weight in grams, oven-dry, at 6 days from $8 \mathrm{~g}$. air-dry seed

\begin{tabular}{|c|c|c|c|c|c|c|}
\hline \multirow[b]{2}{*}{$\begin{array}{c}\text { Concentration } \\
\qquad M\end{array}$} & \multicolumn{2}{|c|}{ Magnesium } & \multicolumn{2}{|c|}{ Strontium } & \multicolumn{2}{|c|}{ Barium } \\
\hline & $\begin{array}{l}\mathrm{MgSO}_{4} \\
\text { alone }\end{array}$ & $\begin{array}{l}+5 \text { p.p.m. } \\
\text { polymyxin }\end{array}$ & $\begin{array}{l}\mathrm{SrCl}_{2} \\
\text { alone }\end{array}$ & $\begin{array}{l}+5 \text { p.p.m. } \\
\text { polymyxin }\end{array}$ & $\begin{array}{l}\mathrm{BaCl}_{2} \\
\text { alone }\end{array}$ & $\begin{array}{l}+5 \text { p.p.m. } \\
\text { polymyxin }\end{array}$ \\
\hline $1 \times 10^{-5}$ & 0.45 & 0.24 & - & - & - & - \\
\hline $1 \times 10^{-4}$ & 0.46 & 0.21 & 0.66 & 0.38 & 0.54 & 0.36 \\
\hline $1 \times 10^{-3}$ & 0.60 & 0.14 & 0.68 & 0.36 & 0.54 & 0.30 \\
\hline $2.5 \times 10^{-3}$ & 0.58 & 0.17 & 0.61 & 0.21 & 0.29 & 0.14 \\
\hline $5 \times 10^{-3}$ & 0.48 & 0.19 & - & - & - & - \\
\hline $1 \times 10^{-2}$ & 0.37 & 0.22 & 0.31 & 0.29 & 0.0 & 0.0 \\
\hline
\end{tabular}

tion, though in the absence of polymyxin the citrate itself somewhat reduced root growth.

Root growth in other species, such as corn, cucumber, and soybean, is also repressed by polymyxin; the repression similarly can be reversed by $1 \times 10^{-2} M$ calcium (Table VI).

In all the experiments reported above, the barley was soaked for $24 \mathrm{hr}$. in water before transfer to polymyxin or salt solutions. Neither the response to polymyxin nor its reversal by calcium was much altered by treating the seeds for an initial period of $24 \mathrm{hr}$. with 5 p.p.m. polymyxin (Table VII). Moreover, if transferred from polymyxin at the end of 2

\section{TABLE $\mathrm{V}$}

Supplementary Effects of Bivalent Cations in Reversing Barley Root Inhibition by 5 p.p.m. Polymyxin

Root weight in grams, oven-dry, at 6 days from $8 \mathrm{~g}$. air-dry seed

\begin{tabular}{llccc} 
Cation & \multicolumn{1}{c}{$\begin{array}{c}\text { Concn. } \\
M\end{array}$} & Yield & $\begin{array}{c}\text { Concn. } \\
M\end{array}$ & Yield \\
$\mathrm{Ca}$ & $1 \times 10^{3}$ & 0.29 & $2.5 \times 10^{-3}$ & 0.45 \\
$\mathrm{Mg}$ & $1 \times 10^{-3}$ & 0.14 & $2.5 \times 10^{-3}$ & 0.17 \\
$\mathrm{Ca}+\mathrm{Mg}$ & $1 \times 10^{-3} \mathrm{each}$ & 0.24 & $2.5 \times 10^{-3} \mathrm{each}$ & 0.65 \\
$\mathrm{Ca}$ & $2 \times 10^{-3}$ & 0.39 & $5 \times 10^{-3}$ & 0.58 \\
$\mathrm{Mg}$ & $2 \times 10^{-3}$ & 0.15 & $5 \times 10^{-3}$ & 0.19 \\
& & & & \\
$\mathrm{Sr}$ & $0.5 \times 10^{-3}$ & 0.37 & $1 \times 10^{-3}$ & 0.36 \\
$\mathrm{Ca}$ & $0.5 \times 10^{-3}$ & 0.30 & $1 \times 10^{-3}$ & 0.29 \\
$\mathrm{Sr}+\mathrm{Ca}$ & $0.5 \times 10^{-3} \mathrm{each}$ & 0.43 & $1 \times 10^{-3} \mathrm{each}$ & 0.32 \\
$\mathrm{Sr}$ & $1 \times 10^{-3}$ & 0.36 & $2 \times 10^{-3}$ & $(0.26)^{\circ}$ \\
$\mathrm{Ca}$ & $1 \times 10^{-3}$ & 0.29 & $2 \times 10^{-3}$ & 0.39
\end{tabular}

a Extrapolated value. 


\section{TABLE VI}

Effect of Polymyxin on Root Growth in Corn, Cucumber and Soybeans

Root weight in grams, oven-dry ${ }^{a}$

$\begin{array}{ccccc}\begin{array}{c}\text { Polymyxin } \\ \text { p.p.m. }\end{array} & \text { Calcium } & \text { Corn Ohio M-15 } & \text { Cucumber Marketer Soybeans Hawkeye } \\ 0 & 0 & 0.47 & 0.20 & 0.22 \\ 5 & 0 & 0.20 & 0.18 & 0.13 \\ 5 & 1 \times 10^{-2} M & 0.56 & 0.25 & 0.24 \\ 0 & 1 \times 10^{-2} M & 0.59 & 0.25 & 0.38\end{array}$

${ }^{a}$ Seed used: corn, 25 g. 6 days; cucumber, 7 g. 8 days; soybeans, 20 g. 6 days.

\section{TABLE VII}

Root Growth in Moore Barley Germinated in 5 p.p.m. Polymyxin or Hater, and Subsequently Treated with Polymyxin and Calcium

\begin{tabular}{|c|c|c|c|}
\hline \multicolumn{3}{|c|}{ Treatment } & \multirow{2}{*}{$\begin{array}{c}\text { Yield } \\
\text { Root weight } \\
\text { g. }\end{array}$} \\
\hline $24 \mathrm{hr}$. & 2nd and 3rd day & 4 th, 5th and 6 th day & \\
\hline Water & Px 5 p.p.m. & Px 5 p.p.m. & 0.30 \\
\hline Water & $\mathrm{Px}+5 \times 10^{-5} M \mathrm{Ca}$ & $\mathrm{Px}+5 \times 10^{-5} \mathrm{M} \mathrm{Ca}$ & 0.28 \\
\hline Water & $\mathrm{Px}+2.5 \times 10^{-3} M \mathrm{Ca}$ & $2.5 \times 10^{-3} M \mathrm{Ca}$ & 0.49 \\
\hline Water & $\mathrm{Px}+2.5 \times 10^{-3} M \mathrm{Ca}$ & $\mathrm{Px}+2.5 \times 10^{-3} M \mathrm{Ca}$ & 0.49 \\
\hline $\mathrm{Px}^{a}$ & Px 5 p.p.m. & Px 5 p.p.m. & 0.28 \\
\hline $\mathrm{Px}$ & $\mathrm{Px}+5 \times 10^{5} \mathrm{M} \mathrm{Ca}$ & $\mathrm{Px}+5 \times 10^{-5} \mathrm{M} \mathrm{Ca}$ & 0.26 \\
\hline $\mathrm{Px}$ & $\mathrm{Px}+2.5 \times 10^{-3} M \mathrm{Ca}$ & $2.5 \times 10^{-3} M \mathrm{Ca}$ & 0.40 \\
\hline $\mathrm{Px}$ & $\mathrm{Px}+2.5 \times 10^{-3} M \mathrm{Ca}$ & $\mathrm{Px}+2.5 \times 10^{-3} M \mathrm{Ca}$ & 0.43 \\
\hline
\end{tabular}

a $\mathrm{Px}$ indicates polymyxin.

\section{TABLE VIII}

Effect of Brief Exposure to Polymyxin on Root Growth of Moore Barley

Seeds were germinated $24 \mathrm{hr}$., transferred to culture vessels in water for 48 hr., treated with polymyxin by immersion at $25^{\circ}$, washed by dipping in several changes of water, and placed in salt solution or water for a further period of 72 hr. Where no polymyxin treatment was given, the roots were put through the same handling operations in water.

$\begin{array}{crcc}\begin{array}{l}\text { Polymyxin treatment } \\ \text { p.p.m. }\end{array} & \text { Sin. } & \text { Root weight } \\ \text { None } & 0 & 1 \times 10^{-2} M \mathrm{Ca} & 8.64 \\ 15 & 15 & \text { Water } & 0.60 \\ 15 & 15 & 1 \times 10^{-2} M \mathrm{Ca} & 0.66 \\ 50 & 15 & 1 \times 10^{-2} M \mathrm{Ca} & 0.65 \\ 100 & 5 & \text { Water } & 0.70 \\ 100 & 15 & 1 \times 10^{-2} M \mathrm{Ca} & 0.46 \\ 100 & 15 & \text { Water } & 0.54 \\ 100 & 60 & 1 \times 10^{-2} M \mathrm{Ca} & 0.38 \\ 100 & 60 & \end{array}$


days, and treated for the remaining 3 days in a calcium solution, the growth was not significantly different than if maintained in polymyxin for the whole period. These data indicated that the initial stages of germination are not particularly sensitive to polymyxin, and that root growth did not immediately return to the normal rate when the polymyxin was withdrawn. The latter observation suggested that in the presence of polymyxin the roots that develop are abnormal, or that polymyxin exposure may cause serious root injury. This was investigated in root-dipping experiments.

It was first established that brief exposure to 5 p.p.m. polymyxin did not appear to affect subsequent root growth, but that if the concentration of antibiotic was increased to 100 p.p.m. subsequent dry-matter yields were reduced (Table VIII). In such experiments 3-day-old roots were dipped briefly in polymyxin, washed thoroughly by dipping in several changes of water, and then returned to the appropriate solution, water or salt, for a further period of 3 days.

It will be noted that if placed in $1 \times 10^{-2} M \mathrm{CaSO}_{4}$ following 100 p.p.m. polymyxin exposure, the barley seedlings developed slightly heavier roots than if subsequently grown in water. The calcium treatment did not, however, neutralize or offset completely the effect of polymyxin exposure. Brief treatment with calcium following polymyxin exposure was less effective than continued treatment. High calcium roots (roots grown in $1 \times 10^{-2} \mathrm{M} \mathrm{Ca}$ ) did not differ from low calcium roots in their response to $1 \mathrm{hr}$. exposure to 100 p.p.m. polymyxin (Table IX).

\section{TABLE IX}

Effect of Calcium Status on Root Growth of Moore Barley T'reated Briefly with Polymyxin

Lots of $8 \mathrm{~g}$. of barley seed were germinated $24 \mathrm{hr}$., transferred to culture vessels in water or $\mathrm{CaSO}_{4}$ for $24 \mathrm{hr}$, , treated with polymyxin by immersion at $25^{\circ}$, washed by dipping several times in several changes of water, and placed in salt solution or water for a further period of $72 \mathrm{hr}$.

\begin{tabular}{|c|c|c|c|c|c|c|}
\hline \multirow[t]{2}{*}{ Pretreatment } & \multicolumn{3}{|c|}{ Polymyxin treatment ${ }^{a}$} & \multirow[t]{2}{*}{ Subsequent medium } & \multicolumn{2}{|c|}{ Root weight } \\
\hline & $h r$. & $p . p . m$. & $\min$. & & $h r$. & $g$. \\
\hline Water & 48 & 100 & 60 & $1 \times 10^{-2} M \mathrm{Ca}$ & 72 & 0.48 \\
\hline Water & 48 & 100 & 60 & Water & 72 & 0.38 \\
\hline Water & 48 & 100 & 60 & $\begin{array}{c}1 \times 10^{-2} M \mathrm{Ca} \\
\text { Water }\end{array}$ & $\begin{array}{r}1 \\
71\end{array}$ & 0.42 \\
\hline $1 \times 10^{-2} M \mathrm{Ca}$ & 48 & 100 & 60 & $1 \times 10^{-2} \mathrm{M} \mathrm{Ca}$ & 72 & 0.43 \\
\hline $1 \times 10^{-2} M \mathrm{Ca}$ & 48 & 100 & 60 & Water & 72 & 0.40 \\
\hline
\end{tabular}

a Each set of roots dipped in $300 \mathrm{ml}$. polymyxin. 
It was observed that the polymyxin solution in which roots were dipped became slightly cloudy or opalescent, and the question therefore arose as to whether some root constituents might not be lost as a result of exposure to polymyxin. Normal roots were obtained by growth in the presence of $0.25 \mathrm{~g}$. Amberlite IRC-50 (Ca) per container for 5 days following $24 \mathrm{hr}$. germination in water. The roots of these seedlings were dipped in 100 p.p.m. polymyxin at $25^{\circ}$ for $1 \mathrm{hr}$. and gently washed in a reproducible manner with several changes of water for $15 \mathrm{~min}$. Some were harvested at this point, while others were replaced in the original calcium Amberlite resin suspension for a further period of $24 \mathrm{hr}$. (Table

TABLE X

Changes in Weight of Moore Barley Roots Following Brief Polymyxin Exposure Treatment sequence

Root weight Ash Ash in roots

1. Water 1 day, Amberlite IRC-50 (Ca), 5 days

2. As 1 , then polymyxin, ${ }^{a} 100$ p.p.m., 1 hr.; water wash, $15 \mathrm{~min}$.

mg.

5. Water 1 day, $2.5 \times 10^{-3} M \mathrm{Ca}, 5$ days; then polymyxin, 100 p.p.m., 1 hr.; water wash, $15 \mathrm{~min}$.

6. Water 1 day, $1 \times 10^{-3} M \mathrm{~K}, 5$ days; then polymyxin, 100 p.p.m., $1 \mathrm{hr}$; water wash, $15 \mathrm{~min}$.
678

$\begin{array}{lll}633 & 1.86 & 11.7\end{array}$

571

776

$\begin{array}{lll}664 & 1.62 & 10.7\end{array}$

$\begin{array}{ccc}78 & 2.55 & m g . \\ & 2.3\end{array}$

$\begin{array}{lll}1 & 1.74 & 9.9\end{array}$

$\begin{array}{lll}446 & 2.37 & 10.6\end{array}$

a Roots from $8 \mathrm{~g}$. seed, air-dry, dipped in $300 \mathrm{ml}$. polymyxin.

X). Not merely was there some loss of weight as a result of the short polymyxin dip, but subsequent growth was halted, and indeed a further loss of weight occurred, presumably by leakage into the culture solution.

This was investigated further in a series of experiments in which normal 6-day roots were dipped in 100 p.p.m. polymyxin for $1 \mathrm{hr}$. at $25^{\circ}$ and, after washing, transferred either to water, $2.5 \times 10^{-3} \mathrm{M} \mathrm{KCl}$, or $2.5 \times 10^{-3} \mathrm{M} \mathrm{CaSO}_{4}$. A control series was handled inan identical manner but dipped only in water prior to transfer to water or salt solution. It was found that all polymyxin-treated roots lost weight as a result of the treatment, and at 7 days weighed only $80-85 \%$ of the 6-day weight, whereas those not polymyxin-treated gained $15-25 \%$ in the seventh day. In the water series, for example, there was a net loss of $134 \mathrm{mg}$. from roots weighing $678 \mathrm{mg}$. prior to polymyxin exposure. Transfer to $\mathrm{KCl}$ or $\mathrm{CaSO}_{4}$ 
solutions following polymyxin treatment did not appreciably reduce the weight loss. However, if roots were dipped in a solution containing both 100 p.p.m. and $10^{-2} \mathrm{M}$ calcium sulfate, no loss in weight was observed. Twenty-four hours later, roots exposed to such a mixture were almost identical in weight to those treated only with $10^{-2} M$ calcium sulfate. The simultaneous presence of the calcium ion, therefore, protected the roots against polymyxin injury, as was demonstrated under somewhat different conditions in Fig. 1.

Both organic and inorganic constituents were lost as a result of the antibiotic treatment. The ash constituents made up only a small part of the total loss (Table $\mathrm{X}$ ). High-salt roots, that is, roots grown in the presence of $2.5 \times 10^{-2} \mathrm{M} \mathrm{CaSO}_{4}$ or $1 \times 10^{-3} \mathrm{M} \mathrm{KCl}$, did not react differently in this respect from the low-salt roots grown in cultures containing only the Amberlite resin IRC-50 (Ca) as calcium supplement.

Spectrographic analysis showed that some cations passed into the polymyxin dip solution (Table XI), and root analysis confirmed the fact that these losses continued into the wash water or subsequent culture medium (Table XII). Twenty-four hours after polymyxin exposure, roots contained both lower percentages and lower absolute amounts of the three major cations, $\mathrm{Ca}, \mathrm{K}$, and $\mathrm{Na}$. Such cation losses were prevented if calcium was present concurrently (Table XIII).

Further, as a result of brief exposure to 100 p.p.m. polymyxin, roots lost their capacity for cation uptake at the usual rate. Data in Tablc XIV show again that the root weight $24 \mathrm{hr}$. after polymyxin treatment was considerably less than before treatment, and that if placed in calcium

\section{TABLE XI}

Cation Content of Polymyxin Solutions after Treating Moore Barley Roots Culture solution in which roots were grown ${ }^{a}$

\begin{tabular}{cccccc}
\multicolumn{2}{c}{$\mathrm{Ca}^{2}$} & \multicolumn{2}{c}{$\mathrm{K}$} & \multicolumn{2}{c}{$\mathrm{Na}$} \\
0.50 & 0.15 & 8.70 & 2.61 & 1.28 & 0.38 \\
& & & & & \\
1.79 & 0.54 & 45.00 & 13.50 & 1.16 & 0.35 \\
& & & & & \\
2.55 & 0.76 & 4.22 & 1.26 & 1.13 & 0.34 \\
1.00 & 0.30 & 8.38 & 2.51 & 1.70 & 0.51
\end{tabular}

$0.25 \mathrm{~g}$. Amberlite IRC-50

(Ca)

$2.5 \times 10^{-2} \mathrm{MCaSO}_{4}+1$ $\times 10^{-2} \mathrm{M} \mathrm{KCl}$

$2.5 \times 10^{-2} M \mathrm{CaSO}_{4}$

$1.00 \quad 0.30$

4.22
8.38

2.51

1.70

0.51

a Eight grams seed germinated $24 \mathrm{hr}$. in water, then 5 days in culture solution specifed, washed with water, and treated with $300 \mathrm{ml}$. polymyxin, 100 p.p.m. for $1 \mathrm{hr}$. at $25^{\circ}$. Polymyxin solution initially free from $\mathrm{Ca}$ and $\mathrm{K}$, trace $\mathrm{Na}$.

${ }^{b}$ Expressed as mg. per culture. 


\section{TABLE XII}

Cation Content of Roots of Moore Barley before and after Polymyxin Treatment

Root condition ${ }^{x}$

1. Before polymyxin

2. After polymyxin 100 p.p.m., 1 hr., then water wash $15 \mathrm{~min}$.

3. As 2 after additional $24 \mathrm{hr}$. in water with $0.25 \mathrm{~g}$. Amberlite IRC-50 $(\mathrm{Ca})$

$\begin{array}{ccc} & \text { Cation in roots } & \\ \mathrm{Ca} & \mathrm{K} & \mathrm{Na} \\ \mathrm{mg} . & \mathrm{mg} . & \mathrm{mg} .\end{array}$

0.40

4.69

1.72

0.28

2.55

1.21

$\begin{array}{lll}0.23 & 1.91 \quad 0.77\end{array}$

a Eight grams seed germinated $24 \mathrm{hr}$, in water, then grown for 5 days with $0.25 \mathrm{~g}$. Amberlite resin IRC-50 (Ca). Roots dipped in $300 \mathrm{ml}$. polymyxin.

\section{TABLE XIII}

Ash and Cation Content of Roots of Atlas Barley Treated with Polymyxin with and without Calciun

\begin{tabular}{|c|c|c|c|c|c|c|}
\hline \multirow[b]{2}{*}{ Root condition } & \multirow[b]{2}{*}{$\begin{array}{c}\text { Root weight } \\
m g .\end{array}$} & \multirow[b]{2}{*}{$\begin{array}{l}\text { Ash } \\
\%\end{array}$} & \multirow[b]{2}{*}{$\begin{array}{c}\text { Ash roots } \\
m g .\end{array}$} & \multicolumn{3}{|c|}{ Cations in roots } \\
\hline & & & & $\begin{array}{l}\mathrm{Ca} \\
m \mathrm{~g} .\end{array}$ & $\mathrm{Na}$ & $\begin{array}{l}\mathrm{K} \\
\mathrm{mg} .\end{array}$ \\
\hline $\begin{array}{l}\text { 1. Amberlite IRC-50 (Ca), } \\
5 \text { days; then polymy- } \\
\text { xin, } 100 \text { p.p.m., } 1 \mathrm{hr} \text {; } \\
\text { water wash, } 5 \text { min.; wa- } \\
\text { ter } 24 \mathrm{hr} \text {. }\end{array}$ & $\begin{array}{l}507 \\
;- \\
-\end{array}$ & 1.52 & 7.7 & 0.04 & 0.30 & 3.33 \\
\hline $\begin{array}{l}\text { As } 1 \text {, but with } 10^{-2} M \mathrm{Ca}- \\
\mathrm{SO}_{4} \text { added to polymy- } \\
\text { xin. }\end{array}$ & 698 & 2.56 & 17.9 & 0.10 & 0.56 & 7.71 \\
\hline
\end{tabular}

or potassium salt solutions for a further 24-hr. period, there was not significantly more growth or less loss than if placed in water. However, the ash contents of roots placed in salt solutions did not fall as low as if returned to water, though still far below that of normal roots placed in the same solutions. The substantial $\mathrm{K}$ uptake which would be expected of normal roots placed for $24 \mathrm{hr}$. in $2.5 \times 10^{-3} \mathrm{M} \mathrm{KCl}$ was almost completely prevented by the brief polymyxin exposure. This, however, was not the case with calcium, for polymyxin-treated roots placed in calcium sulfate reached the same calcium level as normal roots. It should be noted that transfer to salt solution does appear to reduce the loss of ash constituents by amounts far greater than could be accounted for by uptake of the particular cation of the salt solution, calcium in this respect being more effective than potassium.

$\Lambda$ ttempts were made to follow any changes in concentration in the 


\section{TABLE XIV}

Root Weight, Ash and Cation ('ontents of Moore Barley Seedlings I'ariously Treated

Eight grams seed germinated $24 \mathrm{hr}$. in water then 5 days in culture solution containing $0.25 \mathrm{~g}$. Amberlite resin IRC-50 (Ca), treated with $300 \mathrm{ml}$. polymyxin, 100 p.p.m. for $1 \mathrm{hr}$. at $25^{\circ}$, or similarly with water, washed with water $15 \mathrm{~min}$. and transferred to solution specified for $24 \mathrm{hr}$.

\begin{tabular}{l|l|r|r|r|r|r|r}
\hline $\begin{array}{c}\text { Polymyxin } \\
\text { treated }\end{array}$ & Subsequent culture solution & $\begin{array}{c}\text { Root } \\
\text { weight }\end{array}$ & Ash & $\begin{array}{l}\text { Ash in } \\
\text { roots }\end{array}$ & \multicolumn{3}{|c|}{ Cations in roots } \\
\hline & & g. & $\%$ & mg. & mg. & mg. & mg. \\
No & None & 0.68 & 2.40 & 16.3 & 0.26 & 5.82 & 0.55 \\
No & Water & 0.79 & 2.09 & 16.5 & 0.26 & 5.45 & 0.34 \\
Yes & Water & 0.54 & 1.38 & 7.4 & 0.17 & 1.72 & 0.21 \\
No & $2.5 \times 10^{-3} M \mathrm{CaSO}_{4}$ & 0.83 & 2.56 & 21.2 & 0.70 & 5.89 & 0.30 \\
Yes & $2.5 \times 10^{-3} M \mathrm{CaSO}_{4}$ & 0.58 & 1.98 & 11.5 & 0.70 & 2.26 & 0.17 \\
No & $2.5 \times 10^{-3} M \mathrm{KCl}$ & 0.84 & 6.38 & 53.5 & 0.15 & 22.50 & $(1.78)^{a}$ \\
Yes & $2.5 \times 10^{-3} \mathrm{M} \mathrm{KCl}$ & 0.57 & 1.78 & 10.1 & 0.17 & 3.50 & 0.26 \\
\hline
\end{tabular}

${ }^{n} \mathrm{NaOH}$ used in error for $\mathrm{KOH}$ in adjusting the $\mathrm{pH}$ of the $\mathrm{KCl}$ solution.

polymyxin solution used for root dipping. Polymyxin is a strongly basic substance which might be bound at cation-retaining sites on the root surface. In the absence of a specific method, recourse was had to a modification of the colorimetric ninhydrin procedure of Troll and Cannan (15) as was used for polymyxin by Newton (16), but which is, of course, not specific. Almost all of these analyses provided no information on possible polymyxin binding, because the apparent polymyxin content of the dip solutions was substantially increased, no doubt due to the loss of ninhydrin-reacting material from the roots (Table XV). This was supported by micro-Kjeldahl determinations on the polymyxin solution used for root dipping, which similarly increased in nitrogen. Worthy of notice, however, is the observation that the apparent polymyxin content of the solutions used to treat high-salt roots was not increased, suggesting that losses of ninhydrin-reacting material were smaller from such seedlings.

Evidence of polymyxin binding to roots was obtained in some parallel experiments at $3^{\circ}$ using sterile bean roots dipped for $10 \mathrm{~min}$. in 100 p.p.m. polymyxin. The polymyxin concentration, as measured by the ninhydrin method, was reduced by $44 \%$. Roots weighing $412 \mathrm{mg}$. when dry adsorbed $3.3 \mathrm{mg}$. polymyxin. Longer exposure or exposure at $25^{\circ}$ resulted 
TABLE XV

Apparent Polymyxin Content of 100 p.p.m. Polymyxin Solution Immediately after Root Dipping

Root culture solution

$0.25 \mathrm{~g}$. Amberlite IRC-50

Water

$2.5 \times 10^{-3} M \mathrm{Ca}+1 \times 10^{-2} M \mathrm{~K}$

$2.5 \times 10^{-3} \mathrm{M} \mathrm{Ca}$

$1 \times 10^{-3} \mathrm{M} \mathrm{K}$
Apparent polymyxin $\mu \mathrm{g} . / \mathrm{ml}^{\mathrm{a}}$

204

193

88

107

97

${ }^{a}$ Dip solution initially $100 \mu \mathrm{g} . / \mathrm{ml}$.

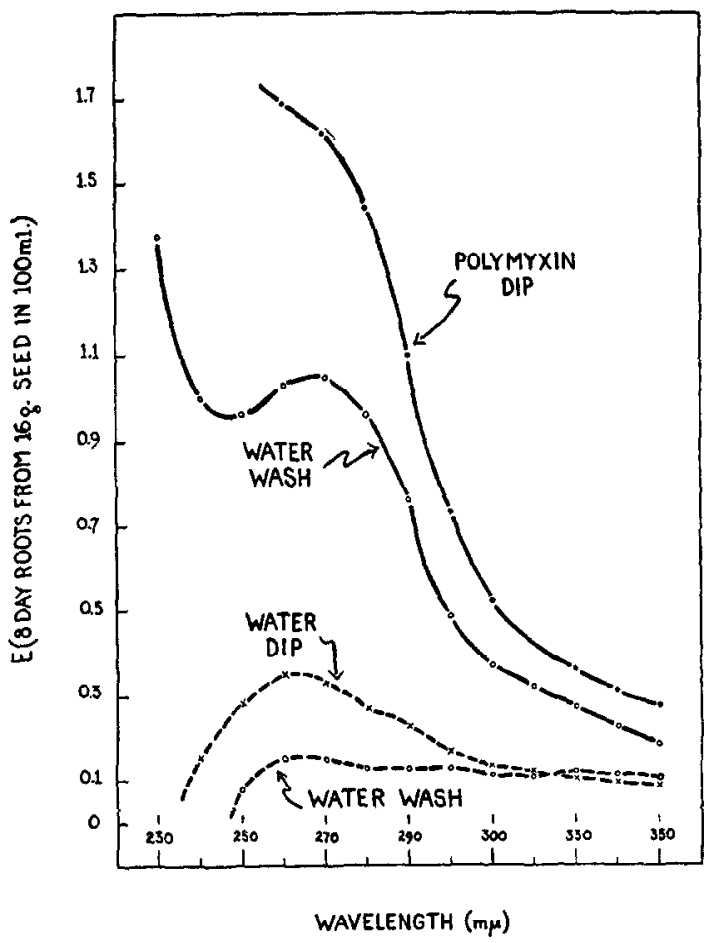

FIG. 2. Absorption spectra of dip or wash solutions obtained in treating roots of corn seedlings (var. Mich. 480). Eight-day roots at $25^{\circ}$ from $16 \mathrm{~g}$. corn treated with $100 \mathrm{ml}$. polymyxin, 100 p.p.m. at $25^{\circ}$ for $1 \mathrm{hr}$. with gentle shaking. Roots then washed with $250 \mathrm{ml}$. distilled water and placed in $100 \mathrm{ml}$. distilled water at $25^{\circ}$ for $4 \mathrm{hr}$.

Upper pair of curves represents the polymyxin dip solution and the 4-hr. water wash liquid.

Lower pair of curves represents liquors obtained by performing the above sequence with water only. 
in an increase in the apparent polymyxin content because of release of ninhydrin-reacting constituents.

In view of the quantitative evidence for loss of root constituents into the polymyxin dip solution and into other solutions in which the roots were subsequently placed, these solutions were examined in an ultraviolet spectrophotometer. The presence of material absorbing strongly at wavelengths less than $280-290 \mathrm{~m} \mu$ was evident. Roots from corn or oats seedlings were excised, washed, and spun gently in a basket centrifuge before treatment for $1 \mathrm{hr}$. with 100 p.p.m. polymyxin. After gentle washing these same roots were placed in water for a further period of $4 \mathrm{hr}$. The polymyxin dip solution and the 4 -hr. water wash liquid were examined in the spectrophotometer after centrifuging to remove any particulate material. Because the mechanical handling involved in these operations might have caused some tissue injury, identical batches of roots were put through the same sequence in water only, and the corresponding treatment liquids were also examined. It was apparent that considerable amounts of substances absorbing strongly in the ultraviolet below $280 \mathrm{~m} \mu$ were present in the polymyxin solution in which corn, barley, or oats roots were placed, and that, after washing, these same

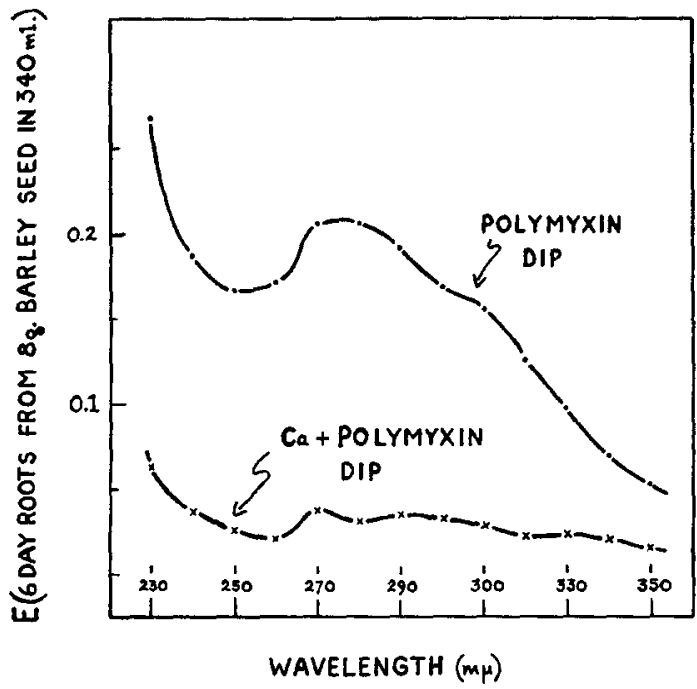

Fig. 3. Absorption spectra of polymyxin and calcium + polymyxin dip solutions obtained in treating roots of barley seedlings (var. Atlas). Normal 6-day roots from $8 \mathrm{~g}$. barley were dipped in $340 \mathrm{ml}$. 100 p.p.m. polymyxin, or 100 p.p.m. polymyxin plus $10^{-2} M \mathrm{CaSO}_{4}$ at $25^{\circ}$ for $1 \mathrm{hr}$. 
roots continued to lose absorbing substances to water in which they were suspended. In the case of corn, at least, the peak absorption appeared to be at approximately $270 \mathrm{~m} \mu$. (Fig. 2). Because excised roots were used, there was a small amount of absorption in the corresponding liquors obtained by carrying out the same operations with water only. The simultaneous presentation of calcium and polymyxin prevented the appearance in the dip solution of material absorbing strongly at wavelengths below $290 \mathrm{~m} \mu$ (Fig. 3).

Parallel dipping experiments were carried out at $3^{\circ}$ but essentially similar results were obtained, though smaller quantitatively. Roots at $3^{\circ}$ lost material absorbing below $290 \mathrm{~m} \mu$ and if subsequently transferred to water at $3^{\circ}$ continued to lose material having a similar absorption spectrum.

\section{Discussion}

These studies demonstrate that polymyxin has profound effects on plant root growth and root properties. This compound inhibited root development of seedlings at concentrations of 5-10 p.p.m. Brief exposure of normal roots to higher concentrations, such as 50-100 p.p.m., resulted in suppression of further growth, and weight loss due to the release of cell constituents into the medium. The inhibitory effect of low concentrations was reversed in the presence of calcium, and in some degree also by other bivalent cations. The damaging effect of brief treatment with higher concentrations was similarly annulled in the presence of calcium.

These observations on the action of polymyxin $\mathrm{B}$ on plant roots parallel to a remarkable degree those made quite independently on bacteria with polymyxin E. For example, growth of Pseudomonas aeruginosa, Pseudomonas denitrificans, Bacillus subtilis, Escherichia coli, and Micrococcus lysodeikticus was inhibited at a level of 5 p.p.m. $(17,18)$. Release of cellular material occurred when washed suspensions of these organisms were treated with 50 p.p.m. polymyxin at $25^{\circ}$ for 20 min., and maximum release took place under these conditions with solutions of 100-200 p.p.m. (18). The material released from bacterial cells absorbed strongly at $260 \mathrm{~m} \mu$ (17). The bactericidal effect at low polymyxin concentrations could be nullified, and the release of cell constituents at higher concentrations prevented, by $0.0025 M \mathrm{Mg}$ and other bivalent cations $(16,19)$. Rapid absorption of polymyxin by washed cells or cell-wall fragments was demonstrated, using a Langmuir-Adam surface balance $(18,20)$.

These findings led Newton (17) and Few and Schulman (18) to con- 
clude that the bactericidal activity of this antibiotic is due to its ability to combine with certain groupings on the cell surface, thereby causing disorganization of the membrane, or those structures therein responsible for the maintenance of osmotic equilibrium. They drew attention to similarities between this antibiotic and certain cationic detergents which also cause release of cell constituents into the medium (21).

In the earlier phases of this work with barley roots, the possibility of formation of a polymyxin-calcium complex was considered, particularly since early growth of the barley seedling is affected by the calcium supply. However, this theory was rejected after determination of the high calcium levels necessary to exert a protective effect in the presence of polymyxin. Instead, it appears probable that calcium and polymyxin are retained at the same absorption sites on the roots, and that to prevent polymyxin absorption a large excess of calcium is required. The root data are not sufficient to establish whether calcium is the only bivalent cation which can wholly offset polymyxin absorption. It was, however, the only cation, bivalent or univalent, found effective in the range of salt concentrations which barley roots tolerate. As soon as the polymyxin molecule is bound to absorption sites on the roots, root behavior is changed. Inorganic and organic cell components are released into the medium and the root no longer has capacity for cation uptake. These responses could not be prevented by subsequent immersion in calcium or other salt solutions, though the losses of cations and organic constituents were somewhat reduced thereby. Ninhydrin-reacting material appeared both in the polymyxin dip solutions and in aqueous media to which polymyxinexposed roots were transferred. The high absorption shown under 290 $\mathrm{m} \mu$ is suggestive of purine and pyrimidine structures.

One noteworthy difference between the behavior of polymyxin-treated roots and bacterial cells is that if the treatment is carried out at $3^{\circ}$, cellular constituents are released from roots though at a lower rate than at $25^{\circ}$, whereas from $P$ s. aeruginosa cells at $2^{\circ}$ no leakage of cell contents occurs, which latter observation led Newton (17) to postulate participation of an enzyme in the leakage phenomenon.

The response of plant roots to polymyxin exposure depends on direct contact with the antibiotic in solution, and irreversible injury and loss of solutes from the cells occurs only in the zone of exposure. If in the rhizosphere population that densely envelopes root surfaces in soils there are organisms which produce substances having the properties of polymyxin, roots may undergo localized injury, and energy sources for the 
rhizosphere organisms may be released and supplement those which may be lost from the roots if they are exposed to wide fluctuations in moisture supply (22).

\section{ACKNOWLEDGMENTS}

I wish to acknowledge the able assistance given by J. N. Yeatman, M. Hlady, and L. C. Vander Beek in many of the experiments reported herein.

\section{SUMMARY}

Root growth of young seedlings of barley and other species was substantially inhibited when placed in 5-10 p.p.m. solutions of the antibiotic, polymyxin B. The inhibiting effect was suppressed by simultaneous presentation of an excess of calcium ions. Polymyxin solutions of the same concentration had no adverse effect on germination. Brief exposure of normal roots of seedlings to 50-100 p.p.m. polymyxin resulted in cessation of further growth or cation uptake, and irreversible injury accompanied by loss of organic and inorganic constituents from the root cells. Simultaneous presentation of calcium nullified these effects. It appears likely that calcium and polymyxin are retained at the same absorption sites, and that to prevent polymyxin absorption a large excess of calcium cations is required. If absorbed, however, polymyxin causes disorganization of cell membranes to the extent that cell contents are released into the medium. These observations parallel closely the bactericidal action of this antibiotic on certain microorganisms, and suggest that there are general features common to the cell walls of roots and bacteria.

\section{REFERENCES}

1. Stessel, G. J., Leben, C., And Keitt, G., Mycologia 45, 325 (1953).

2. Nickell, L. G., and Finlax, A. C., $J$. Agr. Food Chem. 2, 178 (1954).

3. Stallings, J. H., Bacteriol. Revs. 18, 131 (1954).

4. Pramer, D., Ann. Applied Biol. 40, 617 (1953).

5. Barton, L. V., ANd Macnab, J., Contribs. Boyce Thompson Inst. 17, 419 (1954)

6. Wright, J. M., Ann. Botany (London) [N.S.] 15, 493 (1951).

7. Netien, G., Hutinel, P., and Sotty, O., Compt. rend. soc. biol. 146, 137 (1952).

8. Schopfer, W. H., Grob, E., Besson, G., and Keller, V., Arch. sci. (Geneva) 5, 1 (1952).

9. Irengar, M. R. S., and Starkey, R. L., Science 118, 357 (1953).

10. Rosen, W. G., Proc. Soc. Exptl. Biol. Med. 85, 385 (1954).

11. Benedict, R. G., and Langlykke, A. F., J. Bacteriol. 64, 24 (1947).

12. Brownlee, G., ANd Jones, T. S. G., Biochem. $J .43$, xxv (1948). 
13. Jones, T. S. G., Biochem. J. 43, xxvi (1948).

14. Wrukinson, S., Nature 164, 622 (1949).

15. Trold, W., and Cannan, R. K., J. Biol. Chem. 200, 803 (1953).

16. N.wTon, B. A., Biochem. J. 65, x (1953).

17. Newton, B. A., J. Gen. Microbiol. 9, 54 (1953).

18. Few, A. V., And Schulman, J. H., J. Gen. Microbiol. 9, 454 (1953).

19. Newton, B. A., Nature 172, 160 (1953).

20. Few, A. V., and Schurman, J. H., Biochem. J. 64, 171 (1953).

21. SA LTON, M. R. J., J. Gen. Microbiol. 5, 391 (1951).

22. Katznelson, H., Rouatt, J. W., And Payne, T. M. B., Nature 174, 1110 (1954). 